The Injured Athlete (2nd edition) Ed. D.N. Kulund

J.B. Lippincott \& Co. UK agents Harper \& Row Ltd, 1988, £36.50, 603 pp

ISBN 0-397-50765-8

This is the second edition of The Injured Athlete, first published in 1982, and is a well established text in the United States. The author is a Director of the Sports Orthopaedic Centre at Charlottesville, Virginia and the contributors are from the University of Virginia save one who is from the University of South Carolina.

The book represents a multi-disciplinary approach to the management of the injured athlete. There are 13 chapters covering the responsibilities of the athlete's physician; handicapped athletes' medical problems; nutrition and drugs in athletics; principles of training; strength and conditioning; psychological support; the role of the trainer and manipulative therapy for back injuries. The rest of the text outlines athletic injuries to anatomical regions from the head, face and neck to the

\section{Manual of Sports Surgery}

C.L. Shields Jr.

Springer Verlag, Berlin, 1987, DM 475, ISBN 3-540-96415-0

This illustrated manual of sports surgery is one of a series of surgical manuals produced by the publishers. The aim is to present current surgical techniques using full colour illustrations to demonstrate the operative steps. This particular volume presents those operations most commonly carried out on sportsmen and women at the Kerlan-Jobe Orthopaedic clinic at Inglewood, California.

Twenty-three chapters cover four main topics; shoulder, elbow, knee and ankle. Each chapter deals in some detail with the general considerations and surgical techniques relevant to the conditions affecting these areas. Each section begins with a chapter describing arthroscopy in these joints, further chapters dealing with impingement syndromes, reconstruction techniques, release procedures, nerve transfer and repair of tendons and ligaments. There is also detailed advice on post-operative care and two chapters on the rehabilitation of the upper and the lower extremities.

This is indeed a beautifully produced (C) 1989 Butterworth \& Cu (Publishers) Ltd 0306-3674/89/010046-01 \$03.00 leg, foot and ankle.

The text is easy to read and well illustrated with extensive references for each chapter. One interesting feature is the detailed description of two special programmes for exercising patients as part of rehabilitation, one being described as 'Tubics' in which an exercise programme is devised using a bicycle tyre tube. The other is described as 'Poolex' in which a swimming pool is used for rehabilitation exercises. These emphasize that the book is written in American rather than English.

Aside from these anomalies, the text is comprehensive. Information is detailed but is not difficult to understand Injuries are dealt with in a systematic manner and I enjoyed reading the book. The illustrations throughout are clearly presented. The book represents an excellent reference text for anyone involved in the practice of sports medicine and its price should make it within reach of those seriously interested in sports medicine.

\section{G.R. McLatchie FRCS}

\section{Prosthetic Ligament}

\section{Reconstruction of the Knee}

M.J. Friedman and R.O. Ferkel W.B. Saunders/ Harcourt Brace Jovanovich Limited, Sidcup, 1988, £40 ISBN 0721625592

This publication from North America, is aimed primarily at the US market and consists of 29 chapters from 44 contributors. As a result some of the chapters although interesting are irrelevant to the UK.

As with many multi-author manuals, achieving an overall view of a contentious issue is difficult. The need for carefully evaluating and comparing techniques of approaching reconstruction is stressed by the editors.

The text, tables and drawings are of good quality, although the photographs are rather poor, and do not do this publication justice. This is probably a reflection of the price, which at $£ 40$ represents reasonable value. This publication is recommended for any surgeon interested in reconstruction of the unstable knee.

A.J. Banks FRCS text. The full colour illustrations are clear and uncluttered. The text is detailed but brief and the reader has no difficulty in following the steps. At the end of each chapter is a relevant reference section and additional suggestions for further reading.

I enjoyed this book very much and would recommend it to the serious sports surgeon. It is also an excellent reference text for the orthopaedic surgeon in training and accident surgeons. It may be too expensive for indi-

\section{Surgery and Arthroscopy of the} Knee

W. Müller and W. Hackenbruch Springer Verlag, Berlin, 1988, DM 298, ISBN 3540179828

This book of some 720 pages is quite unusually difficult to review. It is the published proceedings of the 2nd European Congress of Knee Surgery and Arthroscopy and has been edited by two men of exceptional merit and worldwide reputation. Their problem is that some of the papers are simple 'pot boilers' where even the most expert editing can do nothing to raise the level above the mundane.

The book is divided into eight sections, varying from surgical anatomy and biomechanics of the knee through to knee prostheses. As always there is a large section on the patella and exten- vidual purchase, but should certainly be bought for the postgraduate library.

My only complaint was that the text presented to me had all of chapter one on arthroscopy of the shoulder and half of chapter two on impingement syndromes missing. The actual text begins 'in the air' on page 15. This omision must have occurred during binding. I hope that a whole print run has not been so affected as it certainly detracts from the excellence of the book.

G.R. McLatchie FRCS

sor apparatus and on arthroscopic surgery of the meniscus. There is a very useful section both on anterior and posterior cruciate ligaments and their laxities.

In all but one of these sections there are papers of quite exceptional merit amongst the others. It is always invidious to select specific papers but the reviewer feels that the paper from Oxford on mechanics of the knee in the sagittal plane should be a standard text for anyone wishing to further their knowledge of the knee.

There is so much excellent material in this book that I feel it should be in all orthopaedic libraries and probably in the personal libraries of those who have a specific interest in the management of the injured knee.

J.B. King FRCS 